\title{
Radio Frequency Heating of Milk-Effects on Quality, Safety, and Shelf Life Assessed Using Artificial Senses and Chemometric Tools
}

\author{
Ambra R. Di Rosa ${ }^{1, * \mathbb{D}}$, Francesco Leone ${ }^{1}$, Fernando Bressan ${ }^{2}$, Giuseppe Battaglia ${ }^{2}$, \\ Tania Veccia $^{2}$ and Vincenzo Chiofalo ${ }^{3}$ \\ 1 Department of Veterinary Science, University of Messina, 98168 Messina, Italy; francesco.leone190@gmail.com \\ 2 RF Division, Officine di Cartigliano S.p.A., 36050 Cartigliano, Italy; fernando.bressan@cartigliano.com (F.B.); \\ giuseppe.battaglia@cartigliano.com (G.B.); tania.veccia@cartigliano.com (T.V.) \\ 3 Department of Chemical, Biological, Pharmaceutical and Environmental Sciences, University of Messina, \\ 98158 Messina, Italy; vincenzo.chiofalo@unime.it \\ * Correspondence: dirosaa@unime.it; Tel.: +39-090-6766547
}

Received: 30 October 2018; Accepted: 3 December 2018; Published: 7 December 2018

\begin{abstract}
Thermal treatments are widely-used strategies in the food industry to inactivate microorganisms and enzymes in order to guarantee safe products without the need for preservatives, while still prolonging their shelf life. Commercial sterilization usually relies on pressurized hot water or steam, often leading to long process times and to surface dehydration phenomena and overheating. However, from the recent studies in the field of radio frequency heating, it has emerged that food products can be processed with time-temperature regimes that are much milder than those required with conventional techniques, resulting in minimal modification of the sensory and nutritive attributes of the food product itself. In the present work, raw bovine milk was sterilized through a combination of steam and radio frequencies, at various temperatures. Alongside the chemical composition, the $\mathrm{pH}$, acidity, and total mesophilic count have been evaluated before and after the process and at the different exit temperatures, in order to study the impact of this technique on milk quality and safety aspects, during a storage period of 55 days at $+4^{\circ} \mathrm{C}$. Moreover, the organoleptic properties of milk have been studied using artificial senses coupled with chemometrics. Different temperatures lead to homogenous physicochemical and microbiological results, which conform to those expected for a good quality bovine milk. The assessment of flavor and appearance revealed retained or the minimally modified milk sensorial properties. Therefore, RF heating appears to be a suitable technique for the production of safe milk with a prolonged shelf life up to $40-45$ days and without significant alterations of the organoleptic and nutritional attributes.
\end{abstract}

Keywords: radio frequency; heating; milk; quality; safety; shelf life; sensor fusion

\section{Introduction}

Thermal treatments are common strategies used in the food industry to inactivate microorganisms and enzymes in order to guarantee safe products, replacing the utilization of preservatives, and prolonging the shelf life of food [1]. To reduce adverse thermal degradation while still ensuring safety for liquid foods, high-temperature short-time (HTST) processes have been developed [2-4]. This approach, which relies on pressurized hot water or steam, often leads to low heat-transfer rates [5]. Indeed, most food products are dielectric materials, that is, they have poor electrical-conduction properties, which are often associated with a poor thermal conductivity. In other words, it would take a long time to heat a dielectric material [6]. However, the direct interaction between food and electromagnetic energy can significantly reduce the time required to reach the target temperature, leading to an improvement of the organoleptic qualities, the appearance, and the nutritional values 
of the product [4]. Milk, being a highly perishable good, is submitted to heat treatments to eliminate potential pathogens and spoilage organisms, as well as to improve its shelf life $[7,8]$. Pasteurized milk has a keeping quality of about one week at cold storage, while ultra-high temperature (UHT) milk can be held at room temperature for several months [9-11]. On the other hand, the production of this type of milk is related to undesired and thermally-derived alterations, such as a caramelized, "cooked" flavor [12-14]. Therefore, novel manufacturing techniques have been introduced for the production of extended shelf life (ESL) milk, which tastes like fresh milk, but which also has a prolonged shelf life, i.e., up to 4 weeks in the cold chain distribution [11]. From recent studies in the field of radio frequency (RF) heating, it has emerged that food products can be processed with milder time-temperature regimes compared to those required with conventional techniques, resulting in a minimal modification of the product [15]. RF occupies the electromagnetic frequency spectrum comprised between $3 \mathrm{kHz}$ and $300 \mathrm{MHz}$, but this frequency range also includes frequencies adopted in telecommunication systems. In order to avoid interferences between the different applications, the ITU Radio Regulation and the CISPR11 standard define that the specific frequencies allowed for industrial, scientific, and medical applications, with unrestricted radiation limits: $13.56 \mathrm{MHz}, 27.12 \mathrm{MHz}$ and $40.68 \mathrm{MHz}$. The most used frequency worldwide is $27.12 \mathrm{MHz}$, because although a higher frequency results in a more efficient power transfer to the product to be heated, $40.68 \mathrm{MHz}$ is subject to restrictions in many nations [16,17]. In order to generate the high frequency electric field E, a high voltage is generally applied to the applicator, which is a system made of conductors having a geometry designed in order to maximize the energy transfer to the product, as well as to optimize the field distribution into it. In Figure 1, a schematic representation of an RF system is shown.

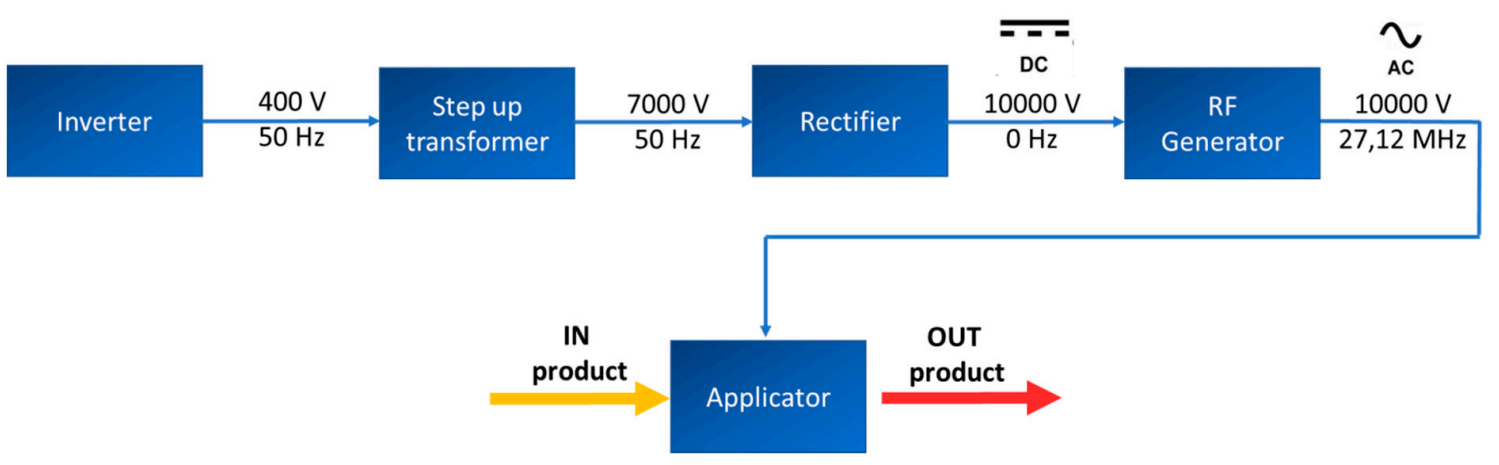

Figure 1. Schematic representation of an RF system.

The inverter regulates the input voltage level and the voltage to the applicator. The step up power transformer increases the voltage level, from low to high voltage. The rectifier circuit transforms the incoming voltage from alternating (AC $50 \mathrm{~Hz}$ ) to direct (DC). The rectifier circuit feeds the oscillating circuit (RF generator) in order to have a high voltage at $27.12 \mathrm{MHz}$ applied to the applicator. The applicator is the last part of the scheme. The applicator is designed to generate and maximize the electric field in the product. As an example, in order to treat liquid products in a pipe, a possible applicator (Figure 2) is composed of an optimized electrode configuration that surrounds a U-shaped Teflon tube, in which the product continuously flows.

Teflon is transparent to RF. The electrodes are drilled metallic discs in which a Teflon pipe is installed. Each of the two vertical pipes is surrounded by electrodes, alternatively connected to the ground and the high voltage link. In RF heating pasteurization processes, the temperature to apply to the product is a parameter set by the operator, while a close loop control optimizes in real time the voltage of the electrodes in order to achieve a very accurate process result. Nowadays, thanks to the use of numerical simulator, it is also possible to design a full 3D multi-physics model (electromagnetic, thermal and fluid-dynamic) of the application and to simulate the process conditions in order to predict the treatment conditions with accuracy $[18,19]$. The main advantage of this technique is the rapid and volumetric generation of heat within the product, which offers uniform heating in short times [4]. 
Due to the high penetration depth of the RF waves, this technique is suitable for food products that are already bottled or packed [16]. Another potential advantage of RF heating in thermal processing is the energy saving. The process can be highly automated, providing a cleaner work environment [4]. Therefore, the aim of this work was to study the impact of different RF heating protocols on quality and safety aspects of raw bovine milk, using artificial senses coupled with chemometric tools. Other authors have investigated the effect of RF heating on dairy products, such as yogurt [20,21] and powder milk [22]; however, this is the first study using electronic senses to achieve this task. Consisting of an array of sensors, exhibiting various selectivity and pattern recognition systems that analyze the sensor responses, this process is inspired by the neurophysiology of the smell and taste [23]. Electronic senses have been used in various research fields; however, most attention has been paid to the food industry [7]. This technology has been dedicated to the automatic analysis of samples with complicated compositions, to the recognition of their characteristic properties, and generally, they are assigned to fast qualitative analysis [23]. Chemical multisensor systems are among the most promising approaches, being direct, rapid, precise, and accurate, with minimal or no sample preparation [24]. In addition, a novel method combining the artificial senses, called "sensor fusion", is increasingly used in food quality assessment, significantly enhancing the performance of the same instruments when used individually [25].

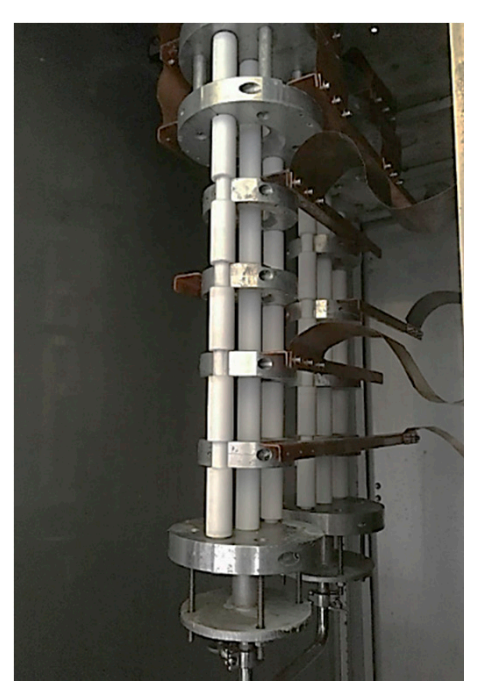

Figure 2. Possible applicator for liquid products.

\section{Materials and Methods}

\subsection{Milk Samples and Heat Treatment}

A lab-scale $2.21 \mathrm{~kW}$ dielectric heater, operating at $27.12 \mathrm{MHz}$, was used to sterilize $1000 \mathrm{~L}$ of raw bovine milk, which was provided from a local manufacturer, and stored at $4{ }^{\circ} \mathrm{C}$. The bulk tank was divided into 11 aliquots of approximatively $90 \mathrm{~L}$. The samples were passed through a conventional pasteurizer, based on a plate heat exchanger, with a flow rate of $150 \mathrm{~L} / \mathrm{h}$. Combinations of steam and RF have been used at various temperatures, ranging from 75 to $125^{\circ} \mathrm{C}$, corresponding to the exit temperature of the dielectric heater, which has been set with a $\Delta \mathrm{T}$ of $15^{\circ} \mathrm{C}$ with respect to that of the pasteurizer. Moreover, the total residence time for the process was $6.9 \mathrm{~s}$. The same manufacturer provided us with UHT and pasteurized milk samples, used for the further comparisons. All the thermal treatments have been carried out at the same location.

\subsection{Alkaline Phosphatase and Lactoperoxidase}

The effectiveness of the treatments has been verified monitoring the residual activities of Alkaline phosphatase (ALP) and Lactoperoxidase (LPO). Milk samples were analyzed for ALP level using the 
Fluorophos system (Advanced Instruments Inc., Norwood, MA, USA), according to the manufacturers' instructions, and the AOAC (Association of Official Analytical Chemists) method 991.24 [26]. Test for LPO has been performed according to Sharma and Rajput (2014) [27]. Negative and positive controls were also prepared and tested [28].

\subsection{Physicochemical and Microbiological Analyses}

Macro-components, e.g., lipids, proteins, lactose, and acidity have been quantified using a MilkoScan FT2 (Foss Electric, Hillerød, Denmark), according to the manufacturers' instructions, and the method ISO (International Standard Organization) 9622:2013 [29]. The measurements of $\mathrm{pH}$ have been performed with a portable $\mathrm{pH}$-meter (XS Instruments, Carpi, Italy). Total mesophilic count (TMC) has been performed in compliance with the method UNI EN ISO 4833-1:2013 [30].

\subsection{Artificial Sensory Analyses}

The analysis of milk aroma is an especially complex problem, as its heterogeneous nature makes difficult to isolate flavor-active chemicals based on general proprieties like polarity or volatility. In this sense, the electronic nose (E-nose), which relies on a non-separative working mechanism, can be seen as a powerful tool for the evaluation of aroma compounds in the volatile fraction of a sample [7,31]. This instrument is defined as a device comprising a vapor sampling system, an array of broadly tuned gas sensors, and an appropriate method for pattern recognition which is capable of recognizing simple or complex odors, and designed to mimic the olfaction of mammals [24]. The E-nose used in this study (FOX 4000, Alpha M.O.S., Toulouse, France) is equipped with an array of 18 MOS (Metal-oxide semiconductor) gas sensors whose resistance is modulated in the presence of a target gas or vapor combined with an automatic headspace sampler HS100. To perform analysis, $1 \mathrm{~mL}$ of each milk sample was pipetted into a septa-sealed screw-cap bottle, and positioned in the auto-sampler racket. Instrumental settings were as follows (Table 1).

Table 1. E-nose settings.

\begin{tabular}{cc}
\hline Acquisition & Oven \\
\hline Duration $120 \mathrm{~s}$ & Incubation time $300 \mathrm{~s}$ \\
Period $1 \mathrm{~s}$ & Incubation temperature $60^{\circ} \mathrm{C}$ \\
Time $1080 \mathrm{~s}$ & Syringe \\
Flow of the carrier gas $150 \mathrm{~mL} / \mathrm{min}$ & Flushing time $120 \mathrm{~s}$ \\
Injection & Temperature $70{ }^{\circ} \mathrm{C}$ \\
Volume $1000 \mu \mathrm{L}$ & Fill speed $500 \mu \mathrm{L} / \mathrm{s}$ \\
Speed $1000 \mu \mathrm{L} / \mathrm{s}$ & Agitator \\
& Speed $500 \mathrm{rpm}$ \\
& On $5 \mathrm{~s}$ \\
& Off $2 \mathrm{~s}$ \\
\hline
\end{tabular}

Chemical compounds showing the five basic taste qualities have been evaluated with an electronic tongue (E-tongue). This analytical tool includes an array of non-specific, poorly selective chemical sensors, with partial specificity, which operates in an aqueous environment, for the recognition of qualitative and quantitative composition of multispecies solutions [32]. A wide variety of chemical sensors can be employed in the design of E-tongues; however, most of these systems are based on potentiometric sensors, of which ion-selective electrodes represent the largest group. The potential of the ion-selective electrodes is a function of the activity of the ionic species in the sample solution, and it is formed in the ion-sensitive membrane, where selective complexation and ion recognition occurs [24]. In this study, a commercially-available E-tongue ( $\alpha$ Astree, Alpha M.O.S., Toulouse, France) was employed. The $\alpha$ Astree measurement system consists of seven potentiometric sensors, specifically designed for food and beverage analysis; an $\mathrm{Ag} / \mathrm{AgCl}$ reference electrode (Metrohm, Ltd., Herisau, Swiss), a mechanical stirrer, a 48-position auto-sampler, and an electronic unit for signal amplification 
and analog to digital conversion. The assays were carried out using aqueous solutions of milk in order to dilute the fat content, which could affect the electric signals recorded from the sensors. The $25 \mathrm{~mL}$ solutions have been prepared with $5 \mathrm{~mL}$ of milk filled with bi-distilled water. Each measurement lasted $120 \mathrm{~s}$, and the sensors were rinsed for $10 \mathrm{~s}$ with bi-distilled water after every acquisition. Measurement data, obtained for each solution, was taken as the average of the last $10 \mathrm{~s}$. Moreover, prior to each analysis cycle, the sensors were conditioned and calibrated with aqueous hydrochloric acid $0.01 \mathrm{M}$ as recommended by the manufacturer [33-35]. Heated milk usually experiences a color change; for this reason, computer vision has been used to control the possible alterations. This technique encloses the capturing, processing, and analysis of two-dimensional images, and aims to duplicate the effect of human vision by electronically perceiving and understanding an image in order to obtain useful information about physical objects [24,36,37]. To perform the analysis, a computer vision system, Iris Visual Analyzer 400 (Alpha M.O.S., Toulouse, France), was used. Milk samples were positioned into the measurement chamber, which guarantees controlled light conditions, and the images were acquired with a black background $[38,39]$. Digital cameras are able to register the color of any pixel from the image using three-color sensors per pixel, which captures the intensity of the light in the red (R), green (G) or blue (B) spectrum [40]. The exploration of data was performed with PCA (Principal Component Analyses). This is a dimension reduction technique which creates a few new variables called "principal components" (PCs) from the linear combination of the original variables, allowing the distribution of samples and variables to be easily plotted and visually analyzed using the Euclidean distance as a similarity metric [24].

\section{Results and Discussion}

\subsection{Effectiveness of the Treatment}

ALP and LPO are two milk' native enzymes which are often used as retrospective indexes for the degree of heating applied during the process of pasteurization, and to discriminate between well-pasteurized and raw or insufficient heat-treated products [41]. ALP is inactivated during the process of pasteurization, while LPO is more heat-stable, and it is inactivated if the milk has been exposed to higher temperatures [42]. Hence, it is expected that a successful treatment will lead to milk where at least ALP is absent. In agreement with this, the fluorimetric assay for ALP was negative for all the samples, while the test for LPO was positive at $75^{\circ} \mathrm{C}$, and negative from $80^{\circ} \mathrm{C}$ onwards. A comparison of the present result with those obtained for pasteurized and UHT milk is given in Table 2.

Table 2. Results for ALP and LPO tests, and comparison with pasteurized and UHT milk.

\begin{tabular}{ccc}
\hline Milk Type & ALP & LPO \\
\hline RF-heated at $75^{\circ} \mathrm{C}$ & Negative & Positive \\
RF-heated at $80^{\circ} \mathrm{C}$ & Negative & Negative \\
RF-heated at $85^{\circ} \mathrm{C}$ & Negative & Negative \\
Pasteurized & Negative & Negative \\
UHT & Negative & Positive \\
\hline
\end{tabular}

\subsection{Physicochemical and Microbiological Properties}

In order to assess the impact of RF heating on safety and quality aspects of milk, physicochemical and microbiological parameters were determined [43-47] before and after the process, at the different exit temperatures. The results obtained for lipids, proteins, lactose, $\mathrm{pH}$, and acidity conform with those expected for a good quality bovine milk, despite a slight fat separation, observed at lower temperatures (Table 3). 
Table 3. Physicochemical and microbiological parameters for good quality bovine milk, raw milk and RF-heated milk.

\begin{tabular}{ccccccc}
\hline Sample & $\begin{array}{c}\text { Lipids } \\
\mathbf{( \% )}\end{array}$ & $\begin{array}{c}\text { Proteins } \\
\mathbf{( \% )}\end{array}$ & $\begin{array}{c}\text { Lactose } \\
(\mathbf{\%})\end{array}$ & $\mathbf{p H}$ & $\begin{array}{c}\text { Acidity } \\
(\mathbf{S H} / \mathbf{5 0} \mathbf{~ m L})\end{array}$ & $\begin{array}{c}\text { TMC } \\
(\mathbf{C F U} / \mathbf{m L})\end{array}$ \\
\hline Good quality bovine milk & $3.4-3.8$ & $3.1-3.4$ & $4.6-4.9$ & $6.5-6.7$ & $2.8-3.8$ & $<50,000$ \\
Raw milk & 3.80 & 3.22 & 4.81 & 6.62 & 3.40 & 56,000 \\
RF-heated milk at $75^{\circ} \mathrm{C}$ & 3.28 & 3.24 & 4.83 & 6.61 & 2.95 & 180 \\
RF-heated milk at $80^{\circ} \mathrm{C}$ & 3.33 & 3.23 & 4.81 & 6.60 & 3.35 & 530 \\
RF-heated milk at $85^{\circ} \mathrm{C}$ & 3.39 & 3.23 & 4.81 & 6.61 & 3.25 & 47 \\
RF-heated milk at $90^{\circ} \mathrm{C}$ & 3.49 & 3.23 & 4.80 & 6.60 & 3.15 & 14 \\
RF-heated milk at $95^{\circ} \mathrm{C}$ & 3.59 & 3.20 & 4.77 & 6.60 & 3.20 & 25 \\
RF-heated milk at $100^{\circ} \mathrm{C}$ & 3.73 & 3.23 & 4.79 & 6.60 & 3.10 & 9 \\
RF-heated milk at $105{ }^{\circ} \mathrm{C}$ & 3.74 & 3.22 & 4.77 & 6.61 & 3.30 & 4 \\
RF-heated milk at $110^{\circ} \mathrm{C}$ & 3.73 & 3.23 & 4.79 & 6.60 & 3.10 & $<1$ \\
RF-heated milk at $115{ }^{\circ} \mathrm{C}$ & 3.72 & 3.19 & 4.76 & 6.61 & 3.35 & $<1$ \\
RF-heated milk at $120^{\circ} \mathrm{C}$ & 3.70 & 3.20 & 4.75 & 6.61 & 3.25 & $<1$ \\
RF-heated milk at $125^{\circ} \mathrm{C}$ & 3.63 & 3.13 & 4.66 & 6.62 & 3.25 & $<1$ \\
\hline
\end{tabular}

Moreover, physicochemical parameters for raw and RF-heated samples are comparable, demonstrating that the heat treatment does not affect the composition of milk, even at high temperatures. Lactose is one of the main ingredients; however, bacteria use it to grow, with the production of lactic acid, which leads to lower $\mathrm{pH}$ values and to an increase in acidity [48]. At the same time, milk coagulation or curdling occurs, along with the development of a characteristic, undesired, "sour" flavor [49]. In general, not-spoiled milk shows acidity from 2.8 to $3.8 \mathrm{SH}^{\circ} / 50 \mathrm{~mL}$, and $\mathrm{pH}$ values from 6.5 to 6.7. In agreement with this, the obtained results conform to those that were expected (Table 3). While physicochemical parameters are retained, a drastic reduction in the TMC values has been observed (Table 3). This is a generic test, widely applied to determine the microbial quality of a product, for those organisms that grow aerobically in the range $25-40{ }^{\circ} \mathrm{C}$, but one which is unable to differentiate among these types of bacteria. According to the Council Directive 92/46/EEC, cow milk that is intended for human consumption should not exceed a TMC of 50,000 CFU $/ \mathrm{mL}$, while the limit for UHT milk is $100 \mathrm{CFU} / \mathrm{mL}$. Therefore, following the radio frequency heating, samples meet the normative requirements. Moreover, at temperatures higher than $85^{\circ} \mathrm{C}$, the sterility is comparable to that of an ultra-high temperature processed milk.

\subsection{Organoleptic Properties}

Fresh, good-quality milk is characterized by three features, namely, (1) a characteristic, subtle, and delicate flavor, (2) a pleasant mouth-feel, since it is an emulsion of fat globules dispersed in a colloidal aqueous solution, and (3) a slightly sweet and salty taste, due to the presence of lactose and salts [7,31]. When we describe the aroma of foods, we often use the term "taste" to indicate sensations that are usually quite complex and include, to a large extent, smell sensations. When we introduce food into our mouth, taste receptors located on the surface of the tongue are stimulated and send signals to the brain. However, at the same time, especially as a result of mastication, many volatile components are also released, and reach the olfactory mucosa through an opening, which is situated on the upper wall of the palate. This combination of sensations is what makes up "flavor" [50]. To reproduce this effect, the sensor outputs were concatenated into a single matrix, with an approach called "data fusion", which combines the outputs of multiple instrumental sources, and which responds to different signature phenomena, increasing the probability of correct classification [24]. Then, the exploration of data was performed with PCA (Figure 3), using the merged data matrix as input. 


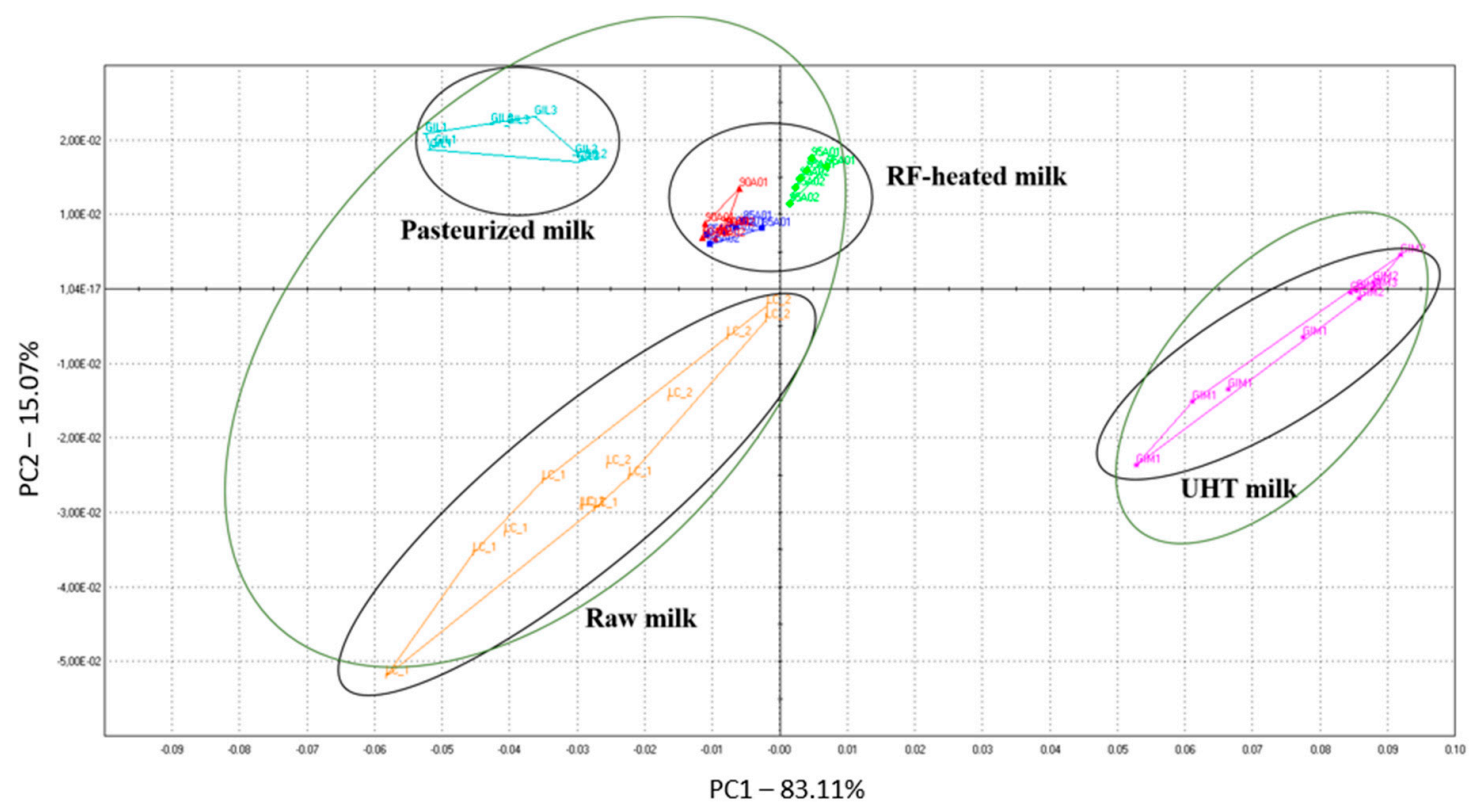

Figure 3. PCA for E-nose and E-tongue merged sensors' outputs. Each different point within the plot refers to different treatment replicates.

"RF-heated" samples overlap each other, and are positioned near the "raw" and "pasteurized milk" clouds, indicating that the different temperatures had the same weak effect on the milk's flavor, which is comparable among the three types of milk. On the other hand, UHT milk is far from the others, because of the thermal treatment leading to the formation of undesired volatile compounds from raw milk components, to the production of off-odors, and to the denaturation of serum proteins, which releases sulfhydryl groups [51]. The colors exhibited from the different samples were used as variables to perform a second PCA (Figure 4).

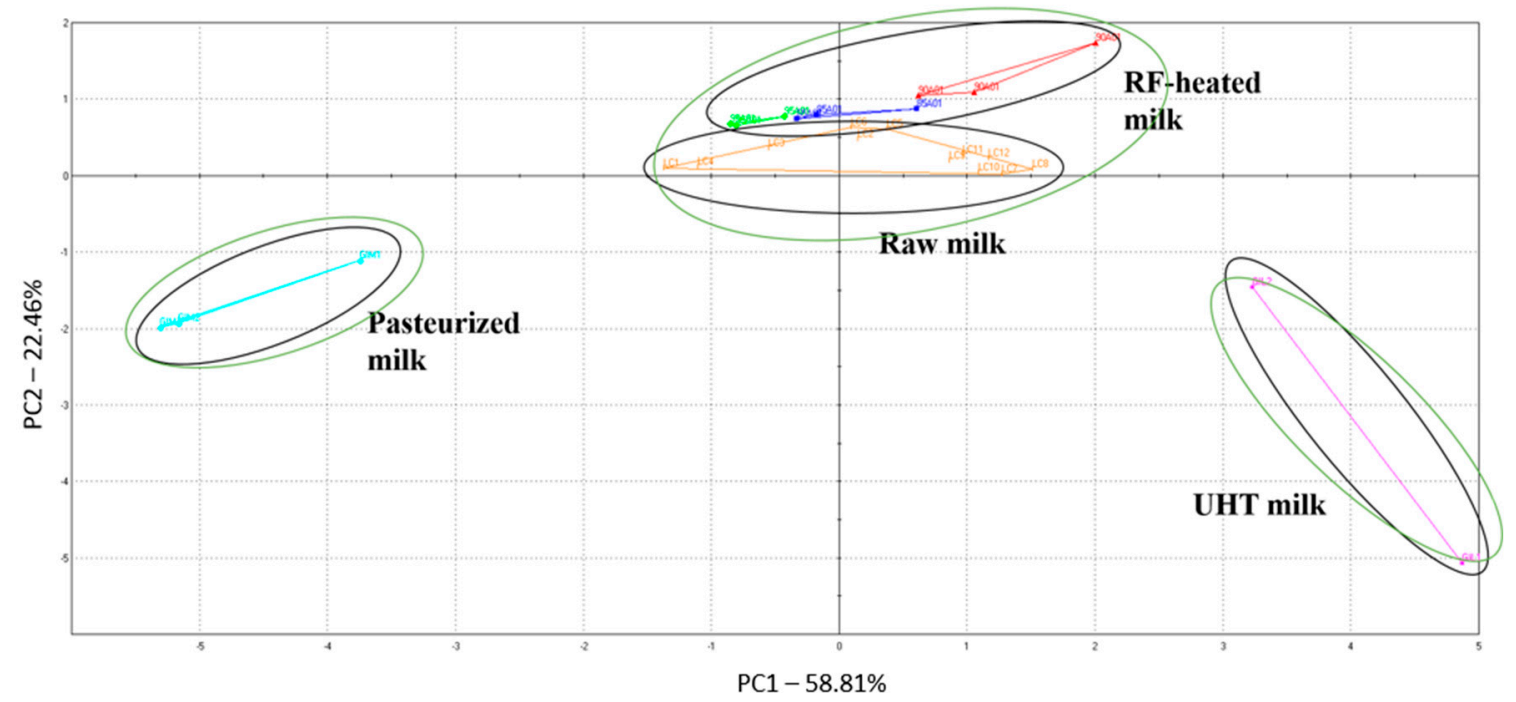

Figure 4. PCA for computer vision. Each different point within the plot refers to different treatment replicates.

RF-heated milk is close to the "raw" samples, indicating a strong resemblance between the appearances of these two groups. On the other hand, pasteurized and UHT milks are far away, at the opposite sides of the scatter plot. Pasteurized milk is on the left, because of the high correlation with the colors (Figure 5). 


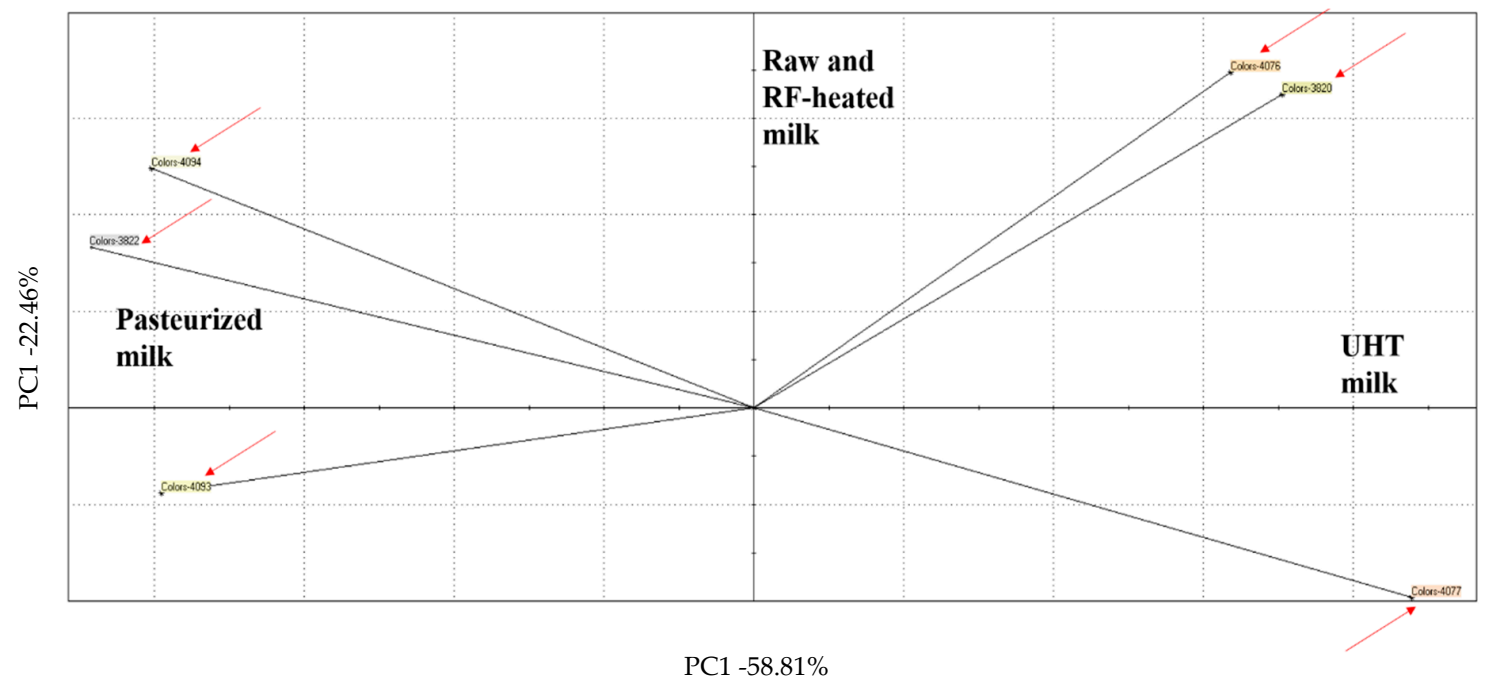

Figure 5. PCA for computer vision with loadings plot.

These colors are associated with the pasteurization process, which also requires a homogenization step that reduces the dimensions of fat globules and casein micelles, and that often results in a whitening effect [52]. On the other hand, UHT milk samples are on the right side of the plot, due to the presence of "burnt" colors, which suggests the beginning of the Maillard reaction, leading to brown-pigmented products, such as pyrazines and melanoidins [53]. Nevertheless, RF-heated samples did not show significant color changes.

\subsection{Shelf Life Evaluation}

The measurements of $\mathrm{pH}$, acidity, and $\mathrm{TMC}$ have been repeated during a storage period of 55 days in order to obtain detailed information regarding the shelf life of milk which was kept at $4{ }^{\circ} \mathrm{C}$ during the duration of the trial. Data acquired at 85,90 , and $95{ }^{\circ} \mathrm{C}$ have been used to obtain the following graphs (Figures 6-8), which show the variation of the investigated parameters over time.

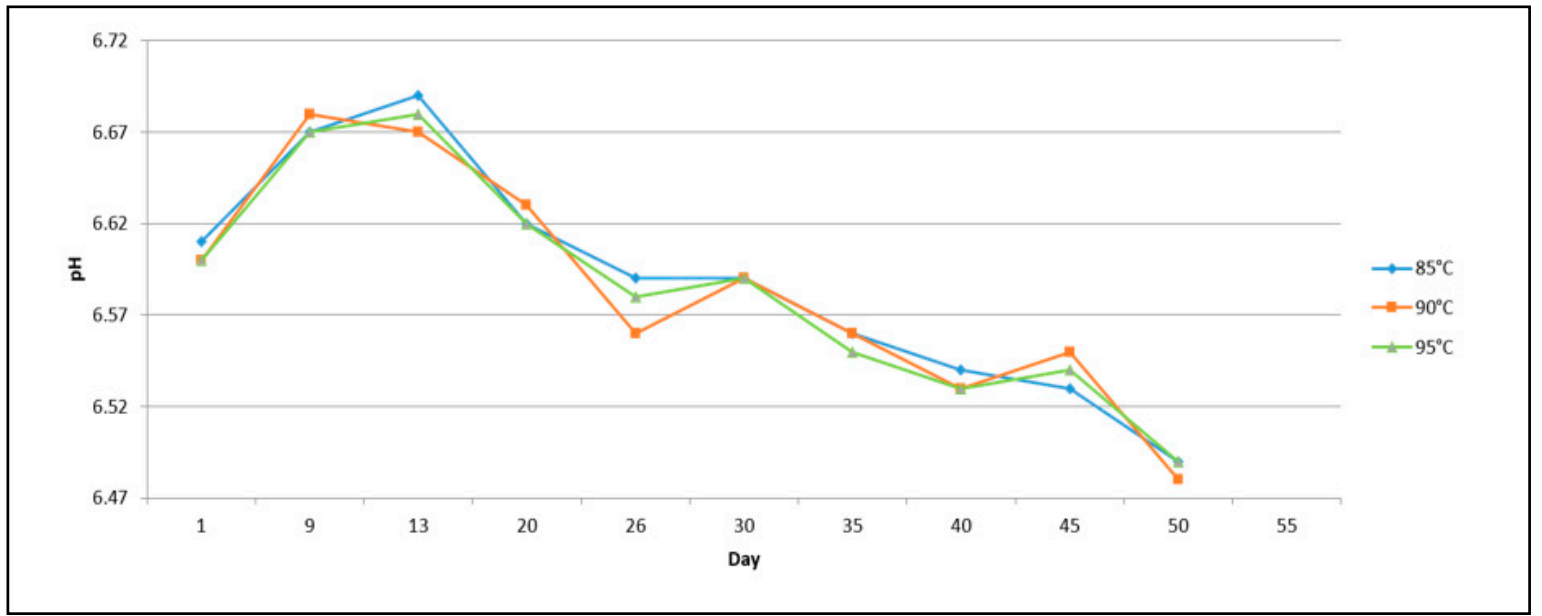

Figure 6. Measurements of $\mathrm{pH}$ during a storage period of 55 days at $4{ }^{\circ} \mathrm{C}$.

Milk undergoes natural degradation; however, normal values for $\mathrm{pH}$, acidity, and TMC have been observed until day 45. In general, commercial ESL milk on the market, which is subjected to heat treatments with temperatures higher than $120^{\circ} \mathrm{C}$, has a shorter shelf life, i.e., approximately 20-25 days. In order to explain the persistent microbial activity that emerged from the trends for $\mathrm{pH}$ and acidity, the spectrum of microbiological investigation should be broadened, considering also extremophile organisms [54]. 


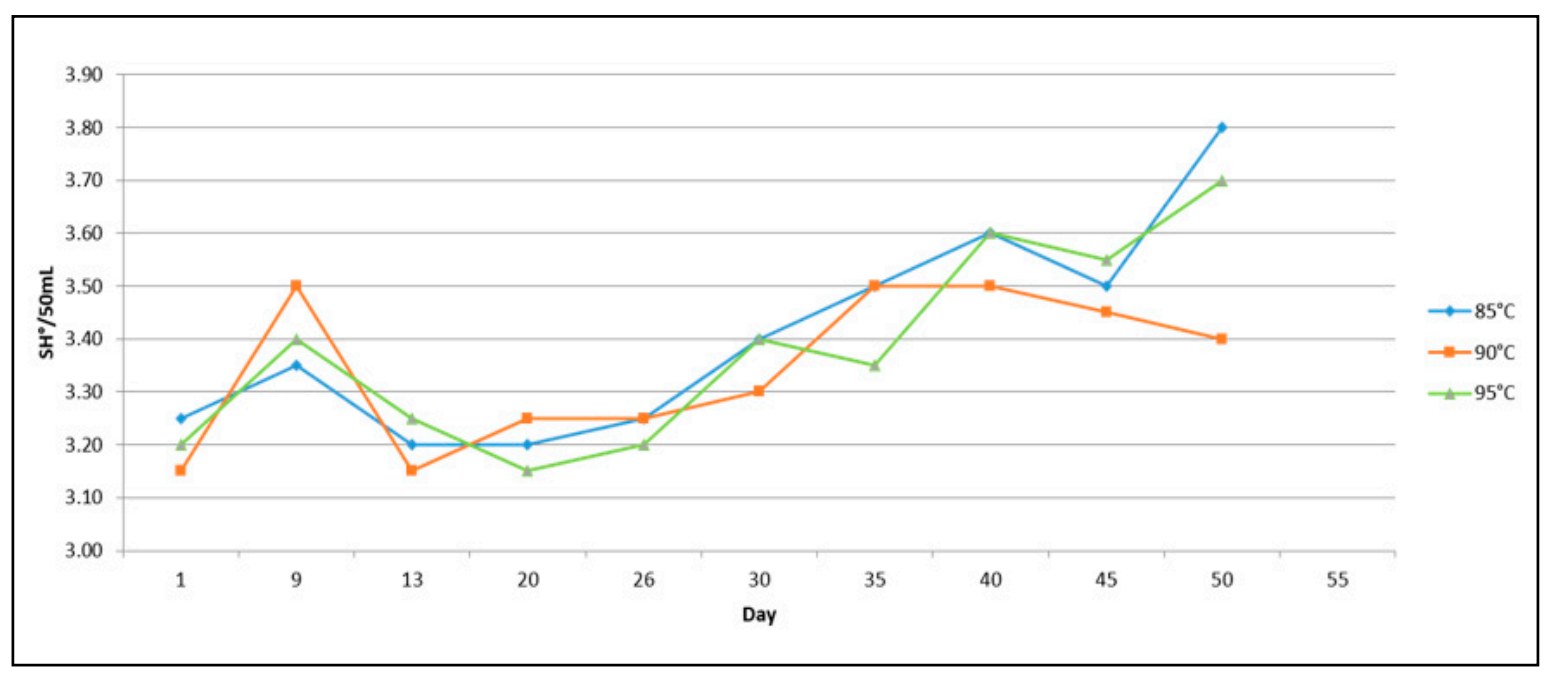

Figure 7. Measurements of acidity during a storage period of 55 days at $4{ }^{\circ} \mathrm{C}$.

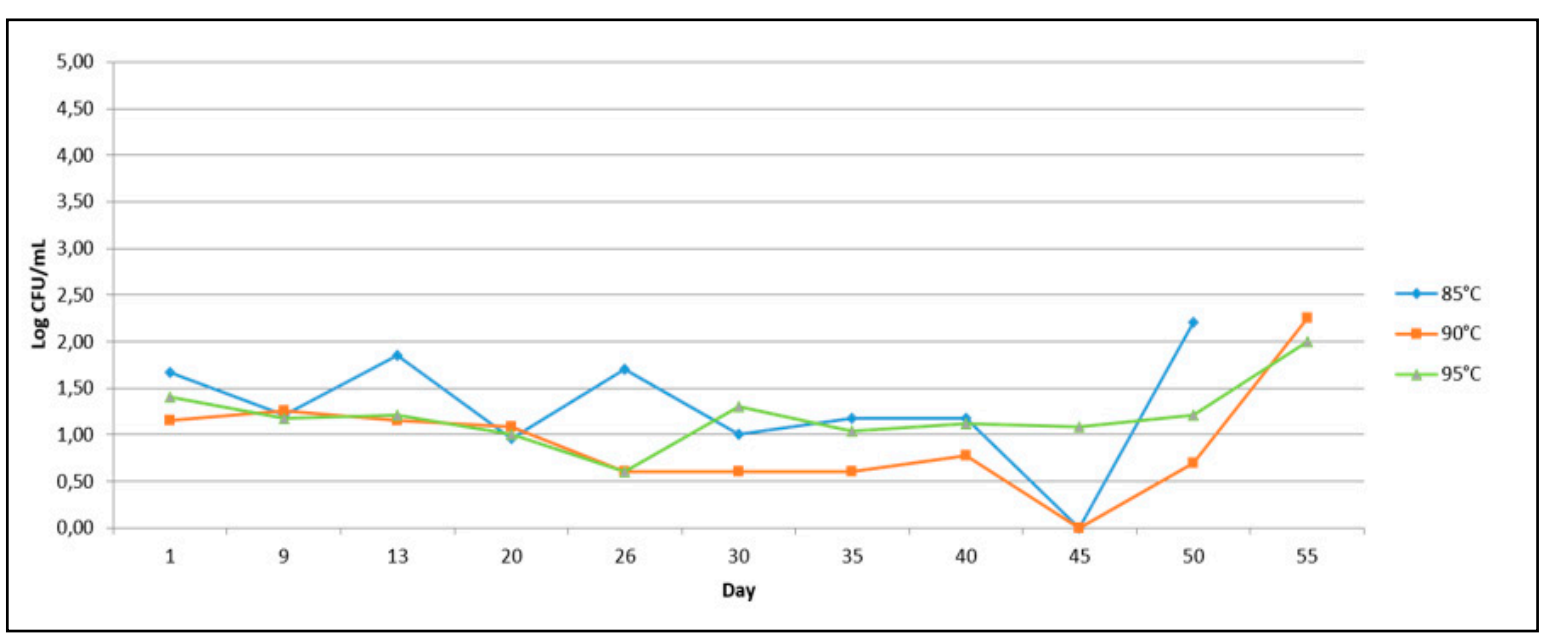

Figure 8. Measurements of TMC during a storage period of 55 days at $4^{\circ} \mathrm{C}$.

\section{Conclusions}

In conclusion, the impact of continuous RF heating on the physicochemical, microbiological, and organoleptic properties of raw milk has been evaluated. Different temperatures lead to homogenous physicochemical and microbiological results, which conform to those expected for a good quality bovine milk, and respect the normative requirements in terms of hygiene. The assessment of flavor and appearance, which has been performed with an innovative combination of electronic senses and data fusion, revealed that the milk's sensorial properties had been retained or minimally modified. Therefore, RF heating appears to be a suitable technique for the production of safe milk with a prolonged shelf life, i.e., of up to 40-45 days in the cold chain distribution, and without significant alterations of the organoleptic and nutritional attributes. Further studies could lead to a true industrial scale-up for the production of ESL milk.

Author Contributions: Conceptualization, A.R.D.R.; Methodology, A.R.D.R. and F.L.; Validation, A.R.D.R., T.V. and F.B.; Formal Analysis, T.V., F.L., G.B. and A.R.D.R.; Investigation, A.R.D.R., T.V. and F.L.; Resources, V.C. and F.B.; Writing-Original Draft Preparation, F.L. and A.R.D.R.; Writing-Review \& Editing, A.R.D.R. and F.B.; Project Administration, A.R.D.R., T.V. and F.B.; Funding Acquisition, V.C. and F.B.

Funding: This research was funded by the Italian Ministry of Education, University and Research (MIUR), Grant Number DM 47495-DAITEC-CUP B22F08000150001.

Conflicts of Interest: The authors declare no conflict of interest. 


\section{References}

1. Harlfinger, L. Microwave sterilization. Food Technol. 1992, 46, 57-61.

2. Meredith, R. Engineers' Handbook of Industrial Microwave Heating; The Institution of Electrical Engineers: London, UK, 1998.

3. Wang, Y.; Wig, T.D.; Tang, J.; Hallberg, L.M. Sterilization of foodstuffs using radio frequency heating. J. Food Sci. 2003, 68, 539-544. [CrossRef]

4. Tang, J.; Chan, T.V.C.T. Microwave and radio frequency in sterilization and pasteurization applications. In Heat Transfer in Food Processing; Yanniotis, S., Ed.; WIT Press Ashurst Lodge: Ashurst, UK, 2007.

5. Luechapattanaporn, K.; Wang, Y.; Wang, J.; Tang, J.; Hallberg, L.M.; Dunne, C.P. Sterilization of scrambled eggs in military polymeric trays by radio frequency energy. J. Food Sci. 2005, 70, E288-E294. [CrossRef]

6. $\quad$ Barber, H. Electroheat; HarperCollins: White Plains, NY, USA, 1983.

7. Di Rosa, A.R.; Leone, F. Application of electronic nose systems on animal source food: An overview. In Handbook of Research on Electronic Noses and Odor Sensing Technology; Albastaki, Y., Albalooshi, F., Eds.; IGI Global: Hershey, PA, USA, 2018. [CrossRef]

8. Zumbo, A.; Scianò, S.; Messina, V.; Di Rosa, A.R.; Assenza, A.; Piccione, G. Metabolical screening in the kid during neonatal period. Large Anim. Rev. 2011, 17, 63-67.

9. Guy, E.J.; Hicks, K.B.; Flanagan, J.F.; Foglia, T.A.; Holsinger, V.H. Effect of Storage of Raw and Pasteurized Goats' Milk on Flavor Acceptability, Psychrotrophic Bacterial Count, and Content of Organic Acids. J. Food Prot. 1985, 48, 122-129. [CrossRef]

10. Renner, E. Storage stability and some nutritional aspects of milk powders and ultra high temperature products at high ambient temperatures. J. Dairy Res. 1988, 55, 125-142. [CrossRef] [PubMed]

11. Schmidt, V.S.J.; Kaufmann, V.; Kulozik, U.; Scherer, S.; Wenning, M. Microbial biodiversity, quality and shelf life of microfiltered and pasteurized extended shelf life (ESL) milk from Germany, Austria and Switzerland. Int. J. Food Microbiol. 2012, 154, 1-9. [CrossRef]

12. Lewis, M.J.; Deeth, H.C. Heat treatment of milk. In Milk Processing and Quality Management; Tamime, A.Y., Ed.; Wiley-Blackwell: Hoboken, NJ, USA, 2009.

13. Mehta, R.S. Milk Processed at Ultra-High-Temperatures-A Review. J. Food Prot. 1980, 43, 212-225. [CrossRef]

14. Shipe, W.F.; Bassette, R.; Deane, D.D.; Dunkley, W.L.; Hammond, E.G.; Harper, W.J.; Kleyn, D.H.; Morgan, M.E.; Nelson, J.H.; Scanlan, R.A. Off Flavors of Milk: Nomenclature, Standards, and Bibliography. J. Dairy Sci. 1978, 61, 855-869. [CrossRef]

15. Kannan, S.; Dev, S.R.S.; Gariepy, Y.; Raghavan, G.S.V. Effect of radiofrequency heating on the dielectric and physical properties of eggs. Prog. Electromagn. Res. B 2013, 51, 201-220. [CrossRef]

16. Marra, F.; Zhang, L.; Lyng, J.G. Radio frequency treatment of foods: Review of recent advances. J. Food Eng. 2009, 91, 497-508. [CrossRef]

17. Hou, L.; Johnson, J.A.; Wang, S. Radio frequency heating for postharvest control of pests in agricultural products: A review. Postharvest Biol. Technol. 2016, 113, 106-118. [CrossRef]

18. Piyasena, P.; Dussault, C.; Koutchma, T.; Ramaswamy, H.S.; Awuah, G.B. Radio frequency heating of foods: Principles, applications and related properties-A review. Crit. Rev. Food Sci. Nutr. 2003, 43, 587-606. [CrossRef] [PubMed]

19. Huang, Z.; Marra, F.; Subbiah, J.; Wang, S. Computer simulation for improving radio frequency (RF) heating uniformity of food products: A review. Crit. Rev. Food Sci. Nutr. 2018, 58, 1033-1057. [CrossRef] [PubMed]

20. Siefarth, C.; Tran, T.B.; Mittermaier, P.; Pfeiffer, T.; Buettner, A. Effect of Radio Frequency Heating on Yoghurt, I: Technological Applicability, Shelf-Life and Sensorial Quality. Foods 2014, 3, 318-335. [CrossRef] [PubMed]

21. Siefarth, C.; Tran, T.B.; Mittermaier, P.; Pfeiffer, T.; Buettner, A. Effect of Radio Frequency Heating on Yoghurt, II: Microstructure and Texture. Foods 2014, 3, 369-393. [CrossRef] [PubMed]

22. Zhong, Y.; Wu, Y.; Zheng, Y.; Zhu, H.; Liu, Z.; Jiao, S. Assessment of radio frequency heating on composition, microstructure, flowability and rehydration characteristics of milk powder. Food Sci. Technol. 2017, 37, 544-551. [CrossRef]

23. Ciosek, P.; Wroblewski, W. Sensor arrays for liquid sensing-Electronic tongue systems. Analyst 2007, 132, 963-978. [CrossRef] [PubMed] 
24. Di Rosa, A.R.; Leone, F.; Cheli, F.; Chiofalo, V. Fusion of electronic nose, electronic tongue and computer vision for animal source food authentication and quality assessment-A review. J. Food Eng. 2017, 210, 62-75. [CrossRef]

25. Borras, E.; Ferré, J.; Boqué, R.; Mestres, M.; Acena, L.; Busto, O. Data fusion methodologies for food and beverage authentication and quality assessment-A review. Anal. Chim. Acta 2015, 891, 1-14. [CrossRef]

26. Angelino, P.D.; Genevieve, L.C.; Marjorie, P.P.; Beattie, S. Residual Alkaline Phosphatase Activity in Pasteurized Milk Heated at Various Temperatures-Measurement with the Fluorophos and Scharer Rapid Phosphatase Tests. J. Food Prot. 1999, 62, 81-85. [CrossRef] [PubMed]

27. Sharma, R.; Rajput, Y.S. Rapid methods for assessing efficiency of heat treatment of milk. J. Food Sci. Technol. 2014, 51, 1416-1420. [CrossRef]

28. Soares, C.F.; Fonseca, C.F.; Leite, M.O.; Oliveira, M.C.P.P. Application of Scharer's quantitative method for the determination of residual alkaline phosphatase activity in standard Minas cheese. Arq. Bras. Med. Vet. Zootec. 2013, 65, 1223-1230. [CrossRef]

29. Zajac, P.; Capla, J.; Vietoris, V.; Zubricka, S.; Curlej, J. Effects of storage on the major constituents of raw milk. Potravinarstvo Slovak J. Food Sci. 2015, 9, 375-381. [CrossRef]

30. Murgia, A.; Scano, P.; Contu, M.; Ibba, I.; Altea, M.; Bussu, M.; Demuru, M.; Porcu, A.; Caboni, P. Characterization of donkey milk and metabolite profile comparison with human milk and formula milk. LWT Food Sci. Technol. 2016, 74, 427-433. [CrossRef]

31. d'Acampora Zellner, B.; Dugo, P.; Dugo, G.; Mondello, L. Milk and dairy foods. In Sensory Analysis of Foods of Animal Origin; Nollet, L.M.L., Toldrà, F., Eds.; CRC Press: Boca Raton, FL, USA, 2011.

32. Ha, D.; Sun, Q.; Su, K.; Wan, H.; Li, H.; Xu, N.; Sun, F.; Zhuang, L.; Hu, N.; Wang, P. Recent achievements in electronic tongue and bioelectronic tongue as taste sensors. Sens. Actuators B Chem. 2015, 207, 1136-1146. [CrossRef]

33. Di Rosa, A.R.; Leone, F.; Scattareggia, C.; Chiofalo, V. Botanical origin identification of Sicilian honeys based on artificial senses and multi-sensor data fusion. Eur. Food Res. Technol. 2018, 244, 117-125. [CrossRef]

34. Di Rosa, A.R.; Leone, F.; Cheli, F.; Chiofalo, V. Novel approach for the characterization of Sicilian honeys based on the correlation of physicochemical parameters and artificial senses. Ital. J. Anim. Sci. 2018, in press. [CrossRef]

35. Di Rosa, A.R.; Marino, A.M.F.; Leone, F.; Corpina, G.G.; Giunta, R.P.; Chiofalo, V. Characterization of Sicilian Honeys Pollen Profiles Using a Commercial E-Tongue and Melissopalynological Analysis for Rapid Screening: A Pilot Study. Sensors 2018, 18, 4065. [CrossRef]

36. Wu, D.; Sun, D.-W. Colour measurements by computer vision for food quality control—A review. Trends Food Sci. Technol. 2003, 29, 5-20. [CrossRef]

37. Timmermans, A.J.M. Computer vision system for on-line sorting of pot plants based on learning techniques. Acta Hortic. 1998, 421, 91-98. [CrossRef]

38. Tretola, M.; Di Rosa, A.R.; Tirloni, E.; Ottoboni, M.; Giromini, C.; Leone, F.; Bernardi, C.E.M.; Dell'Orto, V.; Chiofalo, V.; Pinotti, L. Former food products safety: Microbiological quality and computer vision evaluation of packaging remnants contamination. Food Addit. Contam. A 2017, 34, 1427-1435. [CrossRef] [PubMed]

39. Tretola, M.; Ottoboni, M.; Di Rosa, A.R.; Giromini, C.; Fusi, E.; Rebucci, R.; Leone, F.; Dell'Orto, V.; Chiofalo, V.; Pinotti, L. Former food products safety evaluation: Computer vision as an innovative approach for the packaging remnants detection. J. Food Qual. 2017, 1, 1-6. [CrossRef]

40. Leon, K.; Mery, D.; Pedreschi, F.; Leon, J. Color measurement in L*a*b* units from RGB digital images. Food Res. Int. 2006, 39, 1084-1091. [CrossRef]

41. Buffoli, E.; Fusi, F.; Bolzoni, G. Determinazione della Fosfatasi Alcalina nel latte: Confronto tra metodiche e strumenti. Sci. Tecn. Lattiero-Casearia 2013, 64, 117-125.

42. Ritota, M.; Di Costanzo, M.G.; Mattera, M.; Manzi, P. New trends for the evaluation of heat treatments of milk. J. Anal. Meth. Chem. 2017, 2017, 1864832. [CrossRef] [PubMed]

43. Di Rosa, A.R.; Palucci, A.; Zumbo, A. Climatic effect on milk production of Camosciata goats reared in Calabria. Large Anim. Rev. 2013, 19, 73-78.

44. Zumbo, A.; Di Rosa, A.R.; Billone, B.; Carminati, D.; Girgenti, P.; Di Marco, V. Ripening-induced changes in microbial groups of artisanal Sicilian goats' milk cheese. Ital. J. Anim. Sci. 2009, 8 (Suppl. 2), 450-452. [CrossRef] 
45. Zumbo, A.; Scianò, S.; Messina, V.; Casella, S.; Di Rosa, A.R.; Piccione, G. Haematological profile of messinese goat kids and their dams during the first month post-partum. Anim. Sci. Pap. Rep. 2011, 29, 223-230.

46. Di Rosa, A.R.; Chiofalo, V.; Scianò, S.; Carcione, G.; Zumbo, A. Effect of feed restriction on performances and backfat fatty acid composition of Nero Siciliano growing pigs. Large Anim. Rev. 2012, 18, 117-121.

47. Zumbo, A.; Casella, S.; Di Rosa, A.R.; Scianò, S.; Fazio, F.; Piccione, G. Levels of serum osteocalcin and some electrolytes in foal during the first six months of life (Brief Report). Arch. Anim. Breed. 2010, 53, $239-241$. [CrossRef]

48. Wilkowske, H.H. Relationship between Titratable Acidity and $\mathrm{pH}$ during Lactic Acid Fermentation in Reconstituted Nonfat Milk. J. Food Dairy Sci. 1954, 37, 22-29. [CrossRef]

49. Erkmen, O.; Bozoglu, T.F. Food Microbiology: Principles into Practice; John Wiley \& Sons, Ltd.: Hoboken, NJ, USA, 2016.

50. Persaud, K. Electronic noses and tongues in the food industry. In Electronic Noses and Tongues in Food Sciences; Rodriguez Mendez, M.L., Ed.; Academic Press: Cambridge, MA, USA, 2016.

51. Al-Attabi, Z.; D'Arcy, B.R.; Deeth, H.C. Volatile sulfur compounds in pasteurised and UHT milk during storage. Dairy Sci. Technol. 2014, 94, 241-253. [CrossRef]

52. Walstra, P.; Wouters, J.T.M.; Geurts, T.J. Dairy Science and Technology; CRC Press: Boca Raton, FL, USA, 2006.

53. Morales, F.J.; van Boekel, M.A.J.S. A Study on Advanced Maillard Reaction in Heated Casein/Sugar Solutions: Colour Formation. Int. Dairy J. 1999, 8, 907-915. [CrossRef]

54. Ledenbach, L.H.; Marshall, R.T. Microbiological spoilage of dairy products. In Compendium of the Microbiological Spoilage of Foods and Beverages; Springer: New York, NY, USA, 2009; pp. 41-67.

(C) 2018 by the authors. Licensee MDPI, Basel, Switzerland. This article is an open access article distributed under the terms and conditions of the Creative Commons Attribution (CC BY) license (http:/ / creativecommons.org/licenses/by/4.0/). 